\title{
Integrating Reading, Writing, Listening, and Speaking with Visuals
}

by AYNUR ISMAYILLI KARAKOC

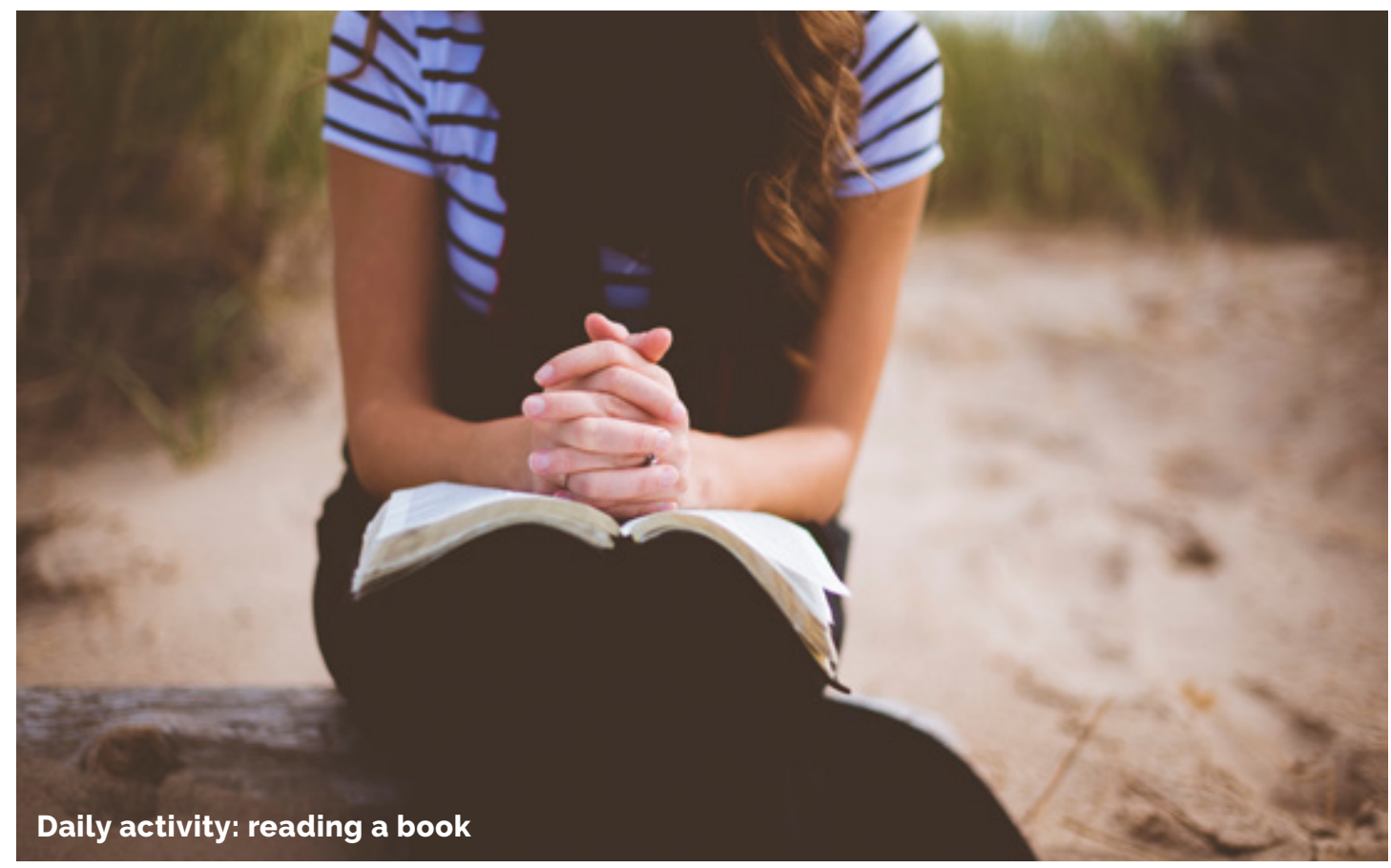

The technique provided here offers an integrated-skills activity. Students should be able to read the description of a visual image, describe their own visuals, read and collect information from other students' writing, and speak about what they have found. This activity can be adapted for nearly any language level. It does not highlight grammar; however, the activity can address a wide range of targeted grammar points, as learners practice using the targeted grammar as they carry out the activity.

The example given here uses the simple past tense as an illustration of how the technique works in practice in an elementary-level class. The required time is approximately 45 minutes; however, that may vary depending on the number of students and other variables.
Necessary materials include a sample visual (photo) with a brief description to provide a model for students; questions related to this description; students' own photos showing any daily activity; an information chart (see Figure 1); glue, tape, or staples; and colorful paper and colored pencils (optional).

Students may use their own photos or other images, including pictures from magazines, newspapers, or the Internet.

\section{PREPARATION}

This example demonstrates how the technique can give students practice using the simple past tense with the general topic of daily activities. Students should already have vocabulary knowledge related to the topic. 
In the class before you intend to begin the activity, tell the students to bring to the next class a visual (picture) of a daily activity. It is acceptable for different students to bring visuals of similar activities, as the main purpose is to engage them in using English. Examples of the daily activities that the pictures might show include the following:

- $\quad$ shopping

- eating out

- playing a sport

- visiting a museum

- reading at the library

\section{PROCEDURE}

1. Show a picture with a description next to it. You might share a photo of yourself eating out with friends. Use the simple past tense to tell the class about when you went out, where you went, whom you went with, what you ate, how the food was, etc. If possible, project the image and description on a screen or whiteboard; if you do not have a projector, you can print out the picture and post it on a wall of the classroom. You might also print out the description and distribute to the students.

2. Distribute questions to students. In pairs, students must answer the questions related to your text. These questions are not designed to measure the reading-comprehension ability of the students, but rather to prepare them for writing. In other words, by answering these questions, students will gain an understanding of what they might include in their writing when they describe their own pictures. The questions should be simple and ask for specific information or details, as in these examples:

- Where did I go yesterday?

- Who went with me?

- What did I do there?

- Did I enjoy it?

Of course, other questions are possible.

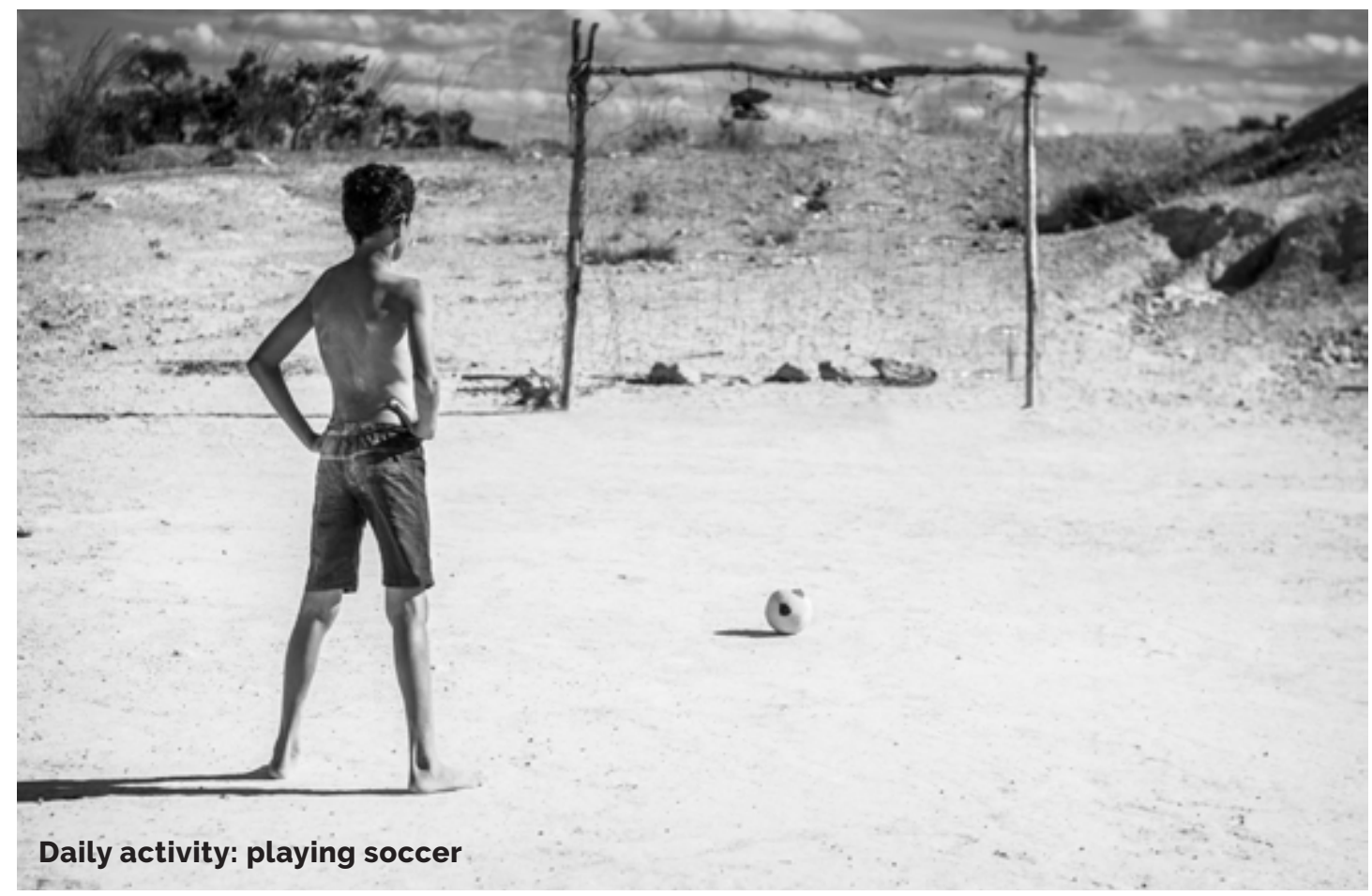


3. Ask students to glue, tape, or staple their picture to a sheet of paper. Ask them to write a description beside it. (This description can be written on a separate piece of paper, which students can glue, tape, or staple to the sheet of paper with the picture.) Your description of your own visual could be a model. Ask students to include similar specific details in their texts. Students may be creative while designing their page; that is, they may use colorful paper, colored pencils, a catchy title, and so on.

4. Give students time to revise their writing. If time allows, have students exchange what they have written with their peers to ensure that essential information has been included; students can also review their own work. You can monitor and help students if necessary.

5. Have students put their page (with picture and writing) on the wall with their names on it.

6. Give the information chart (see Figure 1) to students - or draw it on the board and have students copy it. Each student must read at least three classmates' pages and fill in the information. In other words, each student must collect information about other students. You may adjust the table depending on the number of students in the class. In this step, students move around the class; this movement adds interest and energy to your activity rather than simply having students sit and read or write.

7. After the students finish filling in the chart, ask them to share information. You may want to give an example before having the students share. Depending on the number of students, you may ask each student to talk about only one person, or you might have students share information in groups instead of to the whole class.

8. While one student is sharing information, make sure the other students are listening and cross-checking their own charts to see whether their information matches the information given by the student who is speaking. Later, ask students to tell whether the information given about them was correct.

\section{VARIATIONS}

1. Functional language. To make the activity richer, depending on the time available and the language proficiency of your students, you may add a comments and questions section to the activity. This variation gives students an opportunity to communicate authentically.

\begin{tabular}{|l|l|l|l|}
\hline \multicolumn{2}{|l|}{ Your name: } \\
\hline Questions & $\begin{array}{l}\text { Student A } \\
\text { Name: }\end{array}$ & $\begin{array}{l}\text { Student B } \\
\text { Name: }\end{array}$ & $\begin{array}{l}\text { Student C } \\
\text { Name: }\end{array}$ \\
\hline Where did he/she go? & & & \\
\hline When did he/she go? & & & \\
\hline What did he/she do? & & & \\
\hline Who did he/she go with? & & & \\
\hline Did he/she enjoy ...? & & & \\
\hline What did he/she buy? & & & \\
\hline Any additional information & & & \\
\hline
\end{tabular}




\section{Adding the functional-language element can create a more authentic learning environment, but it is supplementary to the language-skills practice.}

Write comments and questions (see below for suggestions) on slips of paper. The students may use these comments while reading other students' posts during Step 6 of the Procedure. An alternative is for students to write these comments on slips of paper and stick them beside the post that they have read. Make sure, however, that your students know how to use these functional elements. You might suggest using expressions that you have taught before and that are appropriate to the context of this activity; you might also have students practice these comments when you introduce your own visual and description as a model.

Useful expressions appropriate for this context include the following:

(a) Questions:

What did you buy? ... Where did you buy it? ... How much did you pay? ... Did you like the food? ... Did you enjoy the concert/movie?

(b) Compliments:

Nice photo! ... Glad you had fun.

(c) Exclamations:

(What + article + adjective + noun $)$ structure:

What a nice photo! ... What a beautiful place! ... What a lovely car! ... What a delicious meal!

(How + adjective or adverb):

How sweet! ... How lovely! ... How funny! ... How amazing! ... How terrible! ... How romantic!

(d) Other appropriate structures:

I (really) like ; I (really)

want

I really like this place.... I like this idea. ... I really want to visit this museum....

I want to see that movie.

You may need to have students practice these elements so that the task requirements are clear to them and they are able to use the comments and questions appropriately. It is best to keep the sample list short; adding the functional-language element can create a more authentic learning environment, but it is supplementary to the languageskills practice and not the main focus of this technique.

2. Lack of visuals. Images add to the interest and overall impact of the activity, but if there is a lack of visual sources, you may conduct this activity without them, providing only a text description. Similarly, students may rely on their own imagination and write about or describe the topic without referring to visual sources.

Aynur Ismayilli Karakoc teaches at the Foreign Languages School at Okan University in Turkey. She is a Future Leaders Exchange (FLEX) Program alumna and holds an MA in English Language Education from Yeditepe University. 